\section{HIGH-RESOLUTION CARDIAC MAGNETIC RESONANCE PERFUSION IMAGING VS POSITRON EMISSION TOMOGRAPHY FOR THE DETECTION AND LOCALISATION OF CORONARY ARTERY DISEASE}

doi:10.1136/heartjnl-2011-300198.118

G D J Morton, M Ishida, A Chiribiri, A Schuster, S Baker, S Hussain, D Perera, M O'Doherty, S Barrington, E Nagel. King's College London, London, UK

Background Non-invasive imaging has a key role in the detection of coronary artery disease (CAD). Its importance has been affirmed by recent National Institute of Clinical Excellence (NICE) guidelines. Localisation of ischaemia to a coronary territory is also important in patient management. Cardiac Magnetic Resonance (CMR) perfusion imaging is a well-established and radiation-free test for these purposes. However, there are few data comparing perfusion CMR with Positron Emission Tomography (PET), which is widely regarded as the non-invasive gold standard. Furthermore novel CMR methods, including those based on $k-t$ acceleration techniques, allow myocardial perfusion imaging with unprecedented spatial resolution.

Methods 31 patients with known or suspected CAD referred for diagnostic x-ray coronary angiography (XCA) underwent both CMR and PET examinations. Both PET and CMR protocols included adenosine stress and rest perfusion imaging. CMR perfusion imaging was performed at $1.5 \mathrm{~T}$ with a $k$-t-accelerated steady-state free-precession sequence. PET imaging was performed with ${ }^{13} \mathrm{~N}$ Ammonia. The Abstract 118 figure 1 shows an example. Experts blinded to the clinical data analysed the imaging data and experts blinded to the imaging results visually analysed the XCA data. A significant coronary artery stenosis was defined as $\geq 70 \%$ reduction in diameter or a fractional flow reserve $<0.8$ where available. Sensitivity and specificity for PET and CMR vs invasive angiography were calculated. Localisation of ischaemia was assessed in patients with $\mathrm{CAD}$ by classifying myocardial territories as either supplied by, or remote from, a stenotic artery.

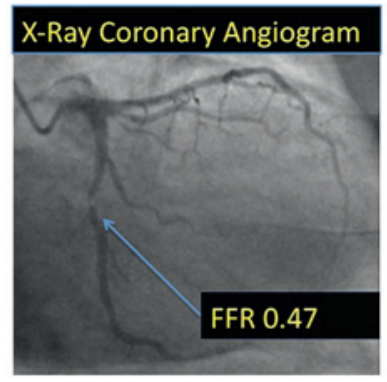

Coronary angiography demonstrates a severe stenosis in the circumflex artery. There is a corresponding perfusion defect in the inferolateral wall during stress PET and CMR imaging.

\section{Abstract 118 Figure 1}

Results Patient characteristics are shown in the Abstract 118 table 1. Mean age $\pm S D$ was $64 \pm 9$ years. One CMR examination was nondiagnostic. The interval between PET and CMR was $2 \pm 6$ days $(77 \%$ same day), between PET and XCA $22 \pm 28$ days and between CMR and XCA $22 \pm 29$ days. The prevalence of CAD was $81 \%$. For the detection of CAD PET sensitivity was $80 \%$ (95\% CI $59 \%$ to $92 \%$ ) and specificity was $67 \%$ (24\% to $94 \%$ ). CMR sensitivity was $83 \%$ (95\% CI 62 to $95 \%$ ) and specificity was also $83 \%$ (36\% to $99 \%$ ). In patients with $\mathrm{CAD}$ ischaemia was localised to $63 \%$ of the territories supplied by stenotic arteries by PET and $76 \%$ by CMR. Remote ischaemia was detected in $24 \%$ of territories by PET and $16 \%$ by CMR.

Abstract 118 Table 1

\begin{tabular}{ll}
\hline Characteristic & $\begin{array}{l}\text { Number (percentage) } \\
\text { of affected patients }\end{array}$ \\
\hline Male & $25(81 \%)$ \\
Diabetes & $12(39 \%)$ \\
Previous PCI & $10(32 \%)$ \\
Hypertension & $22(71 \%)$ \\
\hline
\end{tabular}

Conclusions CMR is at least as accurate as PET for the diagnosis of $\mathrm{CAD}$ and also for the localisation of ischaemia to coronary territories. Relatively low numbers mean that CIs are wide and further work is required. Using an anatomic test as the reference-standard for functional tests has well-described limitations. Remote ischaemia is likely to occur for several reasons including underestimation of disease severity at XCA, microvascular disease and also false positive results.

\section{CARDIOVASCULAR MAGNETIC RESONANCE IMAGING (CMR) DETECTS SUBCLINICAL CARDIOMYOPATHY IN ASYMPTOMATIC PATIENTS WITH LEFT BUNDLE BRANCH BLOCK (LBBB) AND NORMAL ECHOCARDIOGRAPHY}

doi:10.1136/heartjnl-2011-300198.119

M Mahmod, T D Karamitsos, J J Suttie, S G Myerson, S Neubauer, J M Francis. University of Oxford Centre for Clinical Magnetic Resonance Research (OCMR), Oxford, UK

Introduction Asymptomatic left bundle branch block (LBBB) is a common indication for referral for cardiovascular magnetic resonance (CMR) imaging. However, it is not known whether referral for $\mathrm{LBBB}$ returns a high diagnostic yield. We evaluated the diagnostic value of CMR in these patients.

Methods All clinical CMR referrals for LBBB from January 2005 to November 2010 were reviewed by two independent investigators. Only patients with asymptomatic LBBB and normal echocardiograms (echos) who underwent complete CMR evaluation were included in the study. Patients were excluded if they had cardiac symptoms or known coronary artery disease. Anthropometric data, pre-existing conditions, medications, smoking status, family history and echocardiographic data were recorded.

Results From January 2005 to November 2010, 63 asymptomatic patients with $\mathrm{LBBB}$ were referred to our institution for CMR from a total of 3596 CMR referrals. Of these, 34 had normal echos; 20 subjects who had abnormal echos and 9 who had no echos at presentation were excluded from further analysis. Mean age of the 34 patients with normal echos was $54 \pm 9$ years, and 19 (56\%) were men. Demographic data and left ventricular (LV) measurements are presented in the Abstract 119 table 1. The most common associated medical conditions were hypertension (11 patients-33\%) and hyperlipidaemia (8 patients-24\%). Ten subjects (30\%) had a family history of heart disease. Nine $(27 \%)$ patients underwent coronary angiography which was normal. Of the 34 patients, 14 (41\%) were found to have pathological findings on CMR. The commonest abnormalities were dilated cardiomyopathy (DCM) (23\%), followed by LV hypertrophy (LVH-defined as LV wall thickness $>13 \mathrm{~mm}$ ) $(9 \%)$, arrhythmogenic right ventricular cardiomyopathy (ARVC) $(6 \%)$ and Ebstein anomaly (3\%). Two patients $(6 \%)$ had mid wall late gadolinium enhancement. In the remaining 20 (59\%) patients, no abnormalities on CMR were detected. 
Abstract 119 Table 1

\begin{tabular}{lllll}
\hline & $\begin{array}{l}\text { All patients } \\
(\mathbf{n = 3 4 )}\end{array}$ & $\begin{array}{l}\text { Normal CMR } \\
\text { (n= 20) }\end{array}$ & $\begin{array}{l}\text { Abnormal CMR } \\
(\mathbf{n = 1 4 )}\end{array}$ & p value \\
\hline Age (years (median, IQR)) & $54.3 \pm 8.9^{*}$ & $57.5(19.7)$ & $48.5(17.0)$ & 0.6 \\
Male gender (no, \%) & $19(55.8 \%)$ & $11(55.0 \%)$ & $8(57.1 \%)$ & 0.59 \\
BMI (mean, kg/m2) & $28.3 \pm 5.6$ & $27.6 \pm 4.9$ & $29.3 \pm 6.5$ & 0.37 \\
LVEDV (ml (median, IQR)) & $155.0(58.0)$ & $133.0(41.5)$ & $182.5(60.5)$ & 0.012 \\
LVESV (ml (median, IQR)) & $51.0(26.0)$ & $48.0(12.5)$ & $71.5(39.5)$ & 0.005 \\
LVEF (ml (mean, SD)) & $60.6 \pm 13.9$ & $66.1 \pm 5.5$ & $55.7 \pm 13.6$ & 0.004 \\
LV thickness (mm (median, IQR)) & $11.0(7.4)$ & $9.0(6.1)$ & $12.5(9.4)$ & 0.059 \\
LVMI (g/m² (median, IQR)) & $72.5 \pm 18.1^{*}$ & $64.0(15.0)$ & $83.0(14.5)$ & 0.001 \\
\hline
\end{tabular}

*mean, SD. IQR.

Conclusions There is a high rate of sub-clinical cardiomyopathy (41\%) detected by CMR in asymptomatic patients with LBBB despite normal echocardiograms. These findings support the claim that CMR is a valuable adjunct to conventional investigations in asymptomatic LBBB. Further studies are needed to evaluate the prognostic implications of CMR abnormalities in this cohort of patients.

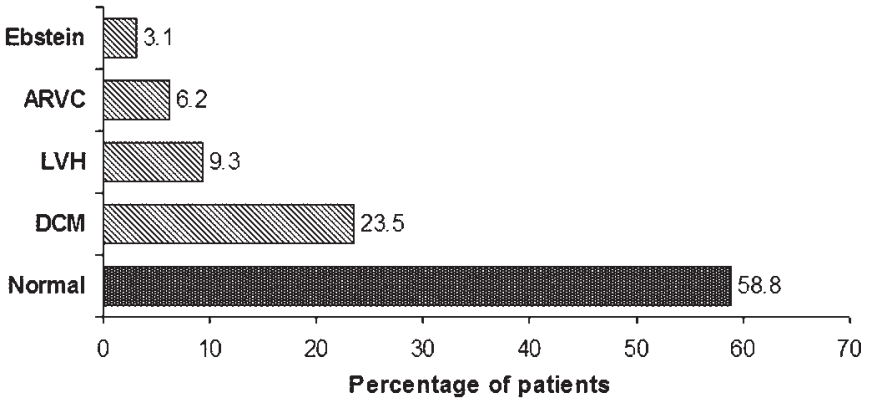

Abstract 119 Figure 1 CMR findings in asymptomatic patients with LBBB and normal echocardiogram.

\section{COMPARISON AND REPRODUCIBILITY OF STANDARD AND HIGH TEMPORAL RESOLUTION MYOCARDIAL TISSUE TAGGING IN PATIENTS WITH SEVERE AORTIC STENOSIS}

doi:10.1136/heartjnl-2011-300198.120

${ }^{1} \mathrm{C}$ D Steadman, ${ }^{2} \mathrm{~N}$ A Razvi, ${ }^{1} \mathrm{~K}$ I E Snell, ${ }^{3} \mathrm{~J}$ P A Kuijer, ${ }^{3} \mathrm{~A}$ C van Rossum, ${ }^{4} \mathrm{G}$ P McCann. 'Leicester Cardiovascular Biomedical Research Unit, Leicester, UK; ${ }^{2}$ Department of Cardiovascular Sciences, University Hospitals of Leicester, Leicester, UK; ${ }^{3}$ Department of Physics and Medical Technology, ICaR-VU, VU University Medical Center, Amsterdam, The Netherlands; ${ }^{4}$ University Hospitals of Leicester, Leicester, UK

Objectives The aim of this study was to compare and assess the reproducibility of left ventricular (LV) circumferential peak systolic strain (PeakEcc) and strain rate (SR) measurements using standard and high temporal resolution myocardial tissue tagging in patients with severe aortic stenosis (AS).

Background Myocardial tissue tagging with cardiac magnetic resonance (CMR) can be used to quantify strain and SR, however, there are little data on the reproducibility. Diastolic SR may be of particular interest as it may be the most sensitive marker of diastolic dysfunction often occurring early in the course of disease.

Methods Eight patients with isolated severe AS without obstructive coronary artery disease were prospectively enrolled. They underwent CMR in a $1.5 \mathrm{~T}$ scanner (Siemens Avanto) on two separate occasions, median interval 12 days. Complementary tagged (CSPAMM) images were acquired with both a single breath-hold (SBH: temporal resolution $42 \mathrm{~ms}$ ), and a multiple brief expiration breath-hold (MBH: high temporal resolution $17 \mathrm{~ms}$ ) sequence. Midwall PeakEcc was measured in the LV at mid-ventricular level with HARP Version 2.7 (Diagnosoft, USA). SR was calculated from the strain data; $S R=E c c 2-E c c 1 / T i m e 2-T i m e 1$. PeakEcc, peak systolic and diastolic SR were read from curves of strain and SR against time.
The MBH SR curves were filtered with a moving average (MA) to reduce noise sensitivity, results from a sample width of three and five were examined. Differences between $\mathrm{SBH}$ and $\mathrm{MBH}$ were assessed using Wilcoxon signed-rank test as not all measures were normally distributed. Reproducibility assessments were carried out on all techniques.

Results PeakEcc was significantly higher with $\mathrm{MBH}$ vs $\mathrm{SBH}$, but reproducibility was slightly worse. Results are summarised in Abstract 120 table 1 . Systolic SR was approximately equal with all techniques although $\mathrm{MBH}$ using $\mathrm{MA}$ of five led to a borderline significant reduction. Diastolic SR was higher when measured with $\mathrm{MBH}$ although only significant using MA of three. Systolic and diastolic SR measures were more reproducible with $\mathrm{MBH}$ compared with SBH, except for the diastolic SR using MA of three, which was substantially worse. Strain and SR curves for the same patient are shown in Abstract 120 figure 1

\section{Abstract 120 Table 1}

\begin{tabular}{|c|c|c|c|}
\hline & $\begin{array}{l}\text { Peak systolic } \\
\text { strain (\%) }\end{array}$ & $\begin{array}{l}\text { Peak systolic } \\
\text { strain rate }(1 / s)\end{array}$ & $\begin{array}{l}\text { Peak diastolic } \\
\text { strain rate }(1 / \mathrm{s})\end{array}$ \\
\hline SBH & $-13.7 \pm 2.4$ & $-0.74 \pm 0.15$ & $0.75 \pm 0.27$ \\
\hline MBH (MA of three) & $\begin{array}{l}-15.1 \pm 3.1 \\
(p=0.023 \text { vs } S B H)\end{array}$ & $\begin{array}{l}-0.73 \pm 0.11 \\
(p=0.877 \text { vs } S B H)\end{array}$ & $\begin{array}{l}1.12 \pm 0.54 \\
(p=0.017 \text { vs } S B H)\end{array}$ \\
\hline MBH (MA of five) & $\begin{array}{l}-15.1 \pm 3.1 \\
(p=0.023 \text { vs } S B H)\end{array}$ & $\begin{array}{l}-0.69 \pm 0.10 \\
(p=0.049 \text { vs SBH })\end{array}$ & $\begin{array}{l}0.91 \pm 0.36 \\
(p=0.535 \text { vs } S B H)\end{array}$ \\
\hline $\begin{array}{l}\text { SBH reproducibility } \\
(\mathrm{MD} \pm \mathrm{SD} ; \mathrm{CoV} ; \mathrm{B}-\mathrm{A})\end{array}$ & $\begin{array}{l}0.50 \pm 1.52 ; 11.1 \% ; \\
-2.5 \text { to } 3.5\end{array}$ & $\begin{array}{l}-0.01 \pm 0.13 ; 18.1 \% ; \\
-0.26 \text { to } 0.28\end{array}$ & $\begin{array}{l}-0.04 \pm 0.16 ; 21.0 \% ; \\
-0.36 \text { to } 0.27\end{array}$ \\
\hline $\begin{array}{l}\text { MBH reproducibility } \\
\text { (MA of three) } \\
\text { (MD } \pm S D ; C o V ; B-A)\end{array}$ & $\begin{array}{l}1.13 \pm 2.23 ; 14.7 \% \text {; } \\
-3.3 \text { to } 5.6\end{array}$ & $\begin{array}{l}0.06 \pm 0.04 ; 5.3 \% \\
-0.02 \text { to } 0.14\end{array}$ & $\begin{array}{l}-0.13 \pm 0.44 ; 39.0 \% ; \\
-1.00 \text { to } 0.75\end{array}$ \\
\hline $\begin{array}{l}\text { MBH reproducibility } \\
\text { (MA of five) } \\
\text { (MD } \pm S D ; C o V ; B-A)\end{array}$ & $\begin{array}{l}1.13 \pm 2.23 ; 14.7 \% \text {; } \\
-3.3 \text { to } 5.6\end{array}$ & $\begin{array}{l}0.04 \pm 0.05 ; 7.8 \% \\
-0.07 \text { to } 0.15\end{array}$ & $\begin{array}{l}0.09 \pm 0.15 ; 16.9 \% \\
-0.39 \text { to } 0.22\end{array}$ \\
\hline $\begin{array}{l}M D \pm S D=\text { mean } \\
\text { difference } \pm S D\end{array}$ & $\begin{array}{l}\mathrm{CoV}=\text { coefficient } \\
\text { of variation }\end{array}$ & $\begin{array}{l}B-A=\text { Bland }- \text { Altman } \\
95 \% \text { limits of agreement }\end{array}$ & \\
\hline
\end{tabular}
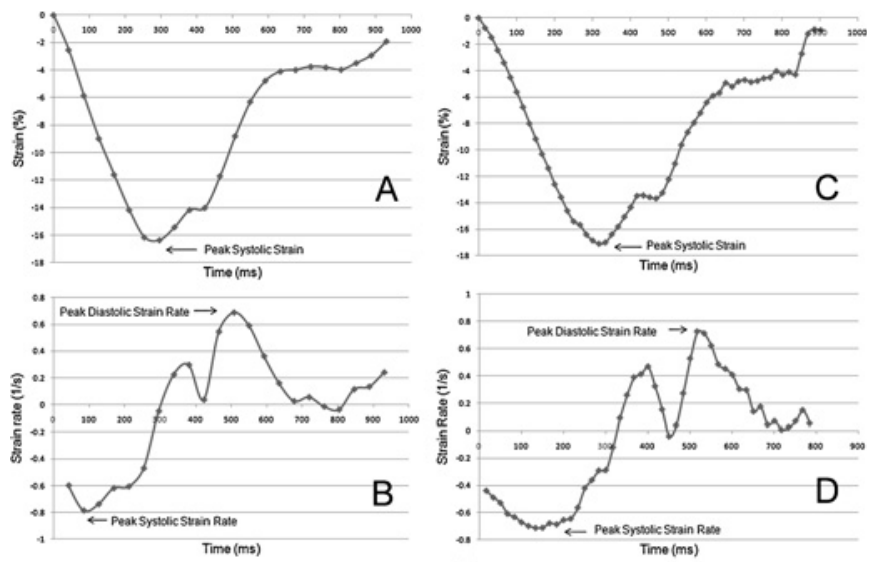

\section{Abstract 120 Figure 1}

Conclusions It is likely than SBH may be adequate or even superior to $\mathrm{MBH}$ for assessment of PeakEcc. The increased temporal resolution of $\mathrm{MBH}$ may be advantageous for examining systolic and diastolic SR; a MA of five for diastolic SR may be the preferred method for quantification given the improved reproducibility of this measure. 